\title{
Dual-qualified Teachers in Vocational Colleges Training Strategy
}

\author{
Ding-Hua HE \\ Wuhan Polytechnic, Wuhan China 430074 \\ hedinghua@qq.com
}

Keywords: Dual-qualified teachers, Construction of teacher, Management mechanism, Incentives.

\begin{abstract}
The vocational institutions cultivate the talents of highly skilled, Cultivation of highly skilled talent needs to rely on the dual-qualified teachers. Wuhan Polytechnic, for example discussed how to create a professional and part of the Double Qualified Teachers; And incentive mechanisms to establish and improve the management of the team of dual-qualified teachers is to establish a system of dual-qualified teachers team protection; Analysis of the management of the dual-qualified teachers and incentive mechanisms, and put forward a number of constructive comments.
\end{abstract}

\section{Introduction}

Vocational education should focus on the structure of teachers, and strengthen professional and part-time professional teaching team building. As early as in 1998, the State Education Commission for the 21 century to deepen the reform of vocational education teaching, for the first time explicitly put forward the concept of " dual-qualified teachers", dual-qualified teachers of vocational institutions should not only have as teachers must have a certain degree of theoretical knowledge, but also to have the engineers have a certain ability to practice. Premier WEN Jiabao in a meeting of the National Vocational Education in 2005 "to vigorously develop vocational education, speed up the training of highly skilled personnel", However, the quantity of teachers lack the low level, especially "dual-qualified teachers" lack prominent bottleneck to implement the policy of "vigorously develop vocational education. Break through this bottleneck is imperative to build a professional and part dual-qualified teachers team, establish and improve the "dual-qualified teachers" management mechanisms and incentives. This section of the text, please refer to References 1 and References 2.

\section{Establish professional and part-time teachers Vocational Double Qualified Teachers}

Dual-qualified teachers is the key to training highly skilled personnel. The vocational colleges shoulders the mission of training the team of dual-qualified teachers, training system should establish a comprehensive team of dual-qualified teachers, Train a batch of sufficient quantity, a solid theoretical and practical ability, high academic standards, strong innovation capability and part of the " dual-qualified teachers" teachers. This paper argues that can be used "send", "training", "decentralization", "leading", "introduction", "engaged" sixth principle to cultivate vocational and part dual-qualified teachers team. This section of the text, please refer to References 3.

\section{"Send" delivery teachers to focus their counterparts in the institutions for further study}

At present, the vast majority of higher vocational colleges are restructured from Specialized secondary schools. for example, Wuhan Polytechnic, merged by Wuhan Radio Technical School, Electronic Industrial School in Hubei Province and Hubei textile industry. Such as this Vocational colleges such part of the teachers' education levels are relatively low, the theoretical foundation is not solid. In response to this reality, the college developed a "Master engineering". The school encourages teachers with lower academic qualifications theory to study, to require teachers must have a master's degree or Master's degree in reading and evaluating the intermediate grade and graduate education tuition reimbursement of a certain proportion of the key institutions professional counterparts. 
In addition, the school spends a lot of money to send young teachers to Germany, Singapore, Australia, the United States, Canada, Finland and other countries for training, learning advanced educational concepts and teaching methods in these countries, and then through the report, engage in lectures and other forms of publicity and promotion.

Delivery teachers to major colleges and universities and foreign learning, mainly for practical ability slightly stronger theoretical level has been the lack of teachers, "send out" way is to train a team of dual-qualified teachers is one important way. This section of the text, please refer to References 3.

\section{"Training" multi-channel training school for teachers}

Through the Multimedia courseware Competition, discusses the professional, discusses the courses taught competitions train dual-qualified teachers. In order to make young teachers grow up quickly. Wuhan polytechnic every year to take the form of a variety of teaching contest. Teachers through competition, through the demonstration of good players in their teaching positions quickly grew up, more and more young teachers rapid growth as the backbone teachers, professional person in charge. In order to consolidate the outcome of the exemplary construction of a national demonstration Polytechnic, in order to develop the dual-qualified teachers, Wuhan polytechnic, discusses the professional, discusses the courses, by these means the selection of professional leaders and course leader. Diversification, a full range of teaching contest, teachers for professional, courses have a deeper understanding of professional standards, teaching theories have been improved, more and more young teachers quickly grew up to become the backbone of teachers, curriculum person in charge of professional leaders to be able to shoulder the training of highly skilled personnel, " dual-qualified teachers.

Educational reform, curriculum reform and train outstanding dual-qualified teachers.

Curriculum reform and professional reform to stimulate the enthusiasm and creativity of our teachers, rich theoretical knowledge of teachers.

Multi-channel culture is the main form of the building and part of the vocational dual-qualified teachers, this kind of training is geared primarily toward full-time teachers, they are the main force in the ranks of the special combination of two qualified teachers.

\section{"Decentralization", it is part of the teachers to the grassroots learning}

Order to adapt to the new situation, the need for the construction of two qualified teachers, specialized teachers must arrange to enterprises and production of the first line of professional practice training, especially the lack of professional practical experience of new teachers. Or use the summer to send teachers under the enterprises to participate in the first line of enterprise production and management. In the "decentralization" process, the practical ability of teachers has been improved every year, the delivery of a large number of teachers "decentralization" during the summer vacation to Foxconn, Taihe, Microsoft corporate, to participate in the production, participate in enterprise management. This "decentralization" process to cultivate the practical ability of the two qualified teachers and management level.

Allow some teachers "decentralization" to the grass-roots level is mainly targeted at the practical ability of poor teachers, this "decentralization" to the grassroots way to quickly improve the practical ability of teachers is one of the important way to create a special combination of vocational dual-qualified teachers.

\section{"Leading", the old help the new, strong help the weak}

The old teachers help the new teachers and the strong teachers help the weak teachers. To ensure that the young teachers are better able to fulfill the responsibilities of teachers, The college in 2006 after the introduction of the new teachers in pre-service training, including: twinning, mentoring and help each other; Organization of young teachers teaching exercises, organization of new teachers for lectures, demonstration lessons taught by experienced teachers play a task; encourage new teachers as counselors, professional teacher; Training methods for teachers just to work near, they are often educated, with a certain degree of theoretical knowledge, but they lack the necessary 
teaching experience. Through the help of the professional leaders, the backbone teachers, teachers of these newly introduced soon grow into dual-qualified teachers both have a certain theoretical knowledge, but also to have some practical ability.

\section{"Introduction", the introduction of technical backbone, academic leaders}

From the introduction of the first line of production management personnel, technical personnel, engaged in the task of teaching of specialized subjects. The introduction of high-wage professional leaders. In the past few years the college has introduced a number of $\mathrm{PhD}$, professor. Employ them as Head of the Department, professional leaders. Lay a solid foundation for the building of dual-qualified teachers.

The introduction of technology backbone, academic leaders including the introduction of both a high level of theory, are strong academic experts and professors, including the introduction of enterprises, institutions and technical experts. This introduction method for dual-qualified teachers in high-end talent.

\section{Conclusion}

Vocational "dual-qualified teachers" the construction of teachers is a systematic project requires not only the efforts of the vocational colleges and the broad participation of the government and enterprises, social. Training vocational dual-qualified teachers should always throughout the career of teachers. The only way to establish a sufficient number of high level of professional and part two qualified teachers team. Establish and perfect the mechanism of the management team of two qualified teachers vocational colleges vocational colleges double teachers training system to protect. The only way to "vigorously develop vocational education, higher vocational education in the spring will really come.

\section{References}

[1] GAO Guiling. Higher vocational college teacher training project design and implementation [M]. Journal of Huazhong Normal University. 2007. 5.

[2] Ministry of Education of the People's Republic of China. Comprehensively improve the quality of Higher Vocational Education [Z]. Department of Higher Education [2006] No.16, November 2006.

[3] WANG Qianxin. Vocational and technical institutions to develop strategic research [M] .WuHan:Huazhong University of Science \& Technology Press Co.,Ltd. 